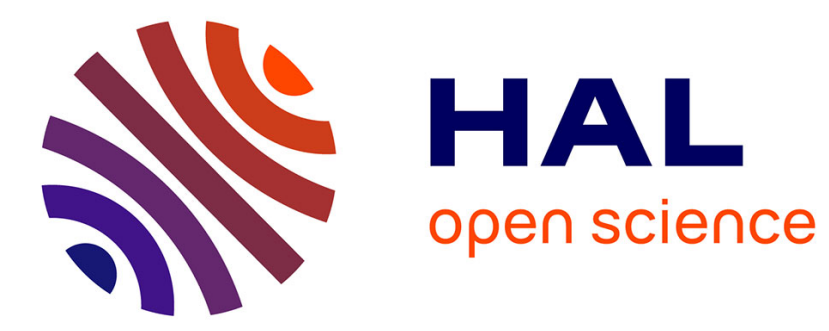

\title{
Monitoring the improvement of an overall industrial performance based on a Choquet integral aggregation
}

\author{
Lamia Berrah, Gilles Mauris, Jacky Montmain
}

\section{To cite this version:}

Lamia Berrah, Gilles Mauris, Jacky Montmain. Monitoring the improvement of an overall industrial performance based on a Choquet integral aggregation. Omega, 2008, 36 (3), pp.340-351. 10.1016/j.omega.2006.02.009 . hal-00353860

\section{HAL Id: hal-00353860 https://hal.science/hal-00353860}

Submitted on 4 Jun 2021

HAL is a multi-disciplinary open access archive for the deposit and dissemination of scientific research documents, whether they are published or not. The documents may come from teaching and research institutions in France or abroad, or from public or private research centers.
L'archive ouverte pluridisciplinaire HAL, est destinée au dépôt et à la diffusion de documents scientifiques de niveau recherche, publiés ou non, émanant des établissements d'enseignement et de recherche français ou étrangers, des laboratoires publics ou privés. 


\title{
Monitoring the improvement of an overall industrial performance based on a Choquet integral aggregation ${ }^{2}$
}

\author{
L. Berrah ${ }^{\mathrm{a}}$, G. Mauris ${ }^{\mathrm{a}, *}, \mathrm{~J}_{\text {. Montmain }}^{\mathrm{b}}$ \\ ${ }^{a}$ Laboratoire d'Informatique, Systèmes, Traitement de l'Information et de la Connaissance, LISTIC, Université de Savoie, \\ BP 806, 74016 Annecy, France \\ ${ }^{\mathrm{b}}$ Laboratoire de Génie informatique et d'ingénierie de la production - ENSTIMA Site EERIE - parc scientifique Georges Besse,
} 30035 Nîmes, France

\begin{abstract}
The design and use of performance measurement systems (PMSs) have received considerable attention in recent years. Indeed, industrial performances are now defined in terms of numerous criteria to be synthesized for overall improvement purposes. The analysis of the literature leads to the conclusion that most of the proposed approaches deal with a qualitative approach of this multi-criteria issue. But only a few quantitative models for PMSs have been proposed in order to better monitor the continuous improvement cycle. Among them, the one proposed by the authors, based on a Choquet integral aggregation operator, allows to express an overall performance according to subordination and transverse interactions between the criteria involved. But, as this model is nonlinear, it is useful to define pieces of information aimed at aiding the manager to improve the performance situation. Thus, this article is a contribution to the managers' requirements for optimizing the improvement of the overall performance versus the allocated resources. In this view, indexes of efficiency and predictive improvement are proposed. The approach is applied to a case study submitted by a company manufacturing kitchen and bathroom furniture which wants to upgrade the monitoring of its "environment and quality improvement plan".
\end{abstract}

Keywords: Performance measurement systems; Choquet integral aggregation; Continuous performance improvement; Resource optimization

\section{Introduction-problem statement}

To deal with the complexity of the current industrial context, new diagnosis/control strategies intended to bring about continuous improvement have to

\footnotetext{
This paper was processed by Guest Editors Margaret M. Wiecek, Matthias Ehrgott, Georges Fadel and José Rui Figueira.

* Corresponding author. Tel.: +1 8082633233 ; fax: +18082633220 .

E-mail addresses: lamia.berrah@univ-savoie.fr (L. Berrah), gilles.mauris@univ-savoie.fr (G. Mauris), jacky.montmain@ema.fr (J. Montmain)
}

include, on the one hand, the multi-criteria performance expression aspects, and on the other hand, the modelling of their relationships [1,2]. Indeed, control strategies have to define, compare and choose action plans with regard to the relationships between performance expressions [1]. The so-called performance measurement systems (PMSs), which are instruments to support decision-making $[1,3,4]$, fulfill that purpose. From a global point of view, a PMS is a multi-criteria instrument for informing decision-makers about a variety of different things, e.g. the level of performance, the reasons for poor or good performance, and the criteria for which improvement is required. A PMS is 
made of a set of performance expressions to be consistently organized with respect to the objectives of the company. For instance, the objectives/performances of the manufacturing workshops contribute to objectives/performances of the manufacturing plants, which in turn contribute to the objectives/performances of the company. Then, in order to support the decision, the set of performances has to be processed so as to compare the different situations. PMSs thus require by nature the use of multi-criteria methods [5]. The main quantitative frameworks used in the PMS literature are aimed at reducing the dimensionality. Thus they are a product of the MAUT aggregation model school [6-10], even though few studies are based on outranking models $[11,12]$. Aggregation models first provide the synthesis of the elementary performance expressions in an overall performance expression. Secondly, they enable to highlight the priorities in the decision-maker's strategy (e.g. investment w.r.t. operators' training). Finally, they make it possible to compare any two described situations by means of their elementary performance expressions.

Our approach falls into the category of aggregation models, and the major problems in the design of such aggregation-based PMSs concern:

- the identification of the performance structure by the break-down of the overall objective considered into elementary ones at different organizational levels (strategic, tactical or operational) [13,14]; and the subsequent aggregation of the elementary performance expressions to obtain the value of the overall one $[15,16]$,

- the expressions of quantified performance reflecting satisfaction of the business process objectives $[17,18]$; and the definition of the pieces of information to be highlighted in order to aid the monitoring of action plans that contribute to performance improvement [19].

Concerning the performance structure, the main industrial practices are based on methodologies that allow linking strategic objectives, structuring tactical and operational criteria affecting them, and designing associated performance expressions $[3,20]$. Causal relationships are generally structured in a tree composed of independent performance criteria. For the quantification, all performance expressions associated with the various heterogeneous criteria are translated into a common reference (generally cost or satisfaction degree). The overall performance is obtained by simply calculating a weighted mean of all the elementary performances. In this line, many approaches proposed in the literature are based on the AHP method (Analytic Hierarchy Process $[1,8,21])$ and its variants $[10,22]$. The drawbacks of this approach are that representing the relationships between performance criteria by a simple independent tree structure is not always straightforward, due to the presence of transverse interactions between criteria (see Section 2). Moreover, these methods suffer from a lack of consistency between the determination of weights and the expression of elementary performances; the former being expressed on a ratio scale not consistent with the interval scale of the latter. That is why, for this purpose, we previously proposed using Choquet integral aggregation operators [23], which are meaningful for performance expressions defined on an interval scale [24]. In this approach, weights and interaction coefficients are determined from decision-makers' preferences in a consistent way $[16,24]$ thanks to an extension of the MACBETH multi-criteria method [25,26].

The point concerning the understanding of the overall performance is little considered in the literature. Indeed, performance improvement is generally not formally considered, as decision-makers tend to take decisions in an intuitive manner. In fact, assuming the Taylorian hypothesis that the overall performance is nothing more than the sum of independent elementary performances simplifies the decision making. But in the current context of transverse interactions between criteria, it has become more difficult for decisionmakers to identify the performance criteria causing a poor overall performance, or presenting a high-priority need of improvement. Therefore, the aim of this paper is to explicitly define, for an overall performance based on a Choquet integral aggregation, pieces of information intended to aid understanding of the causes of poor overall performance and monitoring of improvement initiatives.

From a mathematical point of view, our approach is based on a linear expression by region of the 2 -additive Choquet integral. Indeed, a given ranking of elementary performances determines a simplex region, where the integral is linear. This means that, in such a simplex, conventional linear programming algorithms can be applied to carry out the previous problems of efficiency and improvement analysis.

Thus, in order to respond to managers' questions regarding the monitoring of performance improvement, this paper is organized as follows. Section 2 recalls the characteristics of the industrial performance expressions used to quantify the overall performance. We will particularly present the 2-additive Choquet integral as an interesting solution for handling the interacting multicriteria aspects of industrial performance. Then, in 
Section 3, quantitative performance analysis tools, i.e. efficiency and improvement indexes, are proposed. Section 4 illustrates the proposed approach by means of a practical case study issued from a company that manufactures kitchen and bathroom furniture and storage closets. More precisely, a strategic action plan is considered, the "quality and environment plan". It includes the different actions to be carried out with respect to product quality and environmental constraints. Some concluding discussion and problems to be considered in the future, such as dynamic performance measurement systems (DPMSs), are finally pointed out.

\section{The industrial performance expressions: background}

\subsection{Introduction}

This section is intended to present the way we have used to quantify the performance at different company levels. Indeed, in our view, as well as that of many authors, one key role of a PMS is the computation of the elementary performance expressions and their bottomup aggregation to obtain an overall performance expression [20]. In practice, this quantification phase occurs after a qualitative analysis has been made, which is often based on the knowledge of the management team. Different frameworks are available to achieve this logical qualitative break-down of relationships between the variables involved. They are not detailed here (an overview is presented in [20]) since the emphasis is on the multi-criteria decision-making aspects related with PMSs, i.e. on the expression and analysis of quantified elementary and aggregated performances. Nevertheless, the framework used for the case study is presented at the beginning of Section 4 .

\subsection{Elementary performance expressions}

Broadly speaking, a performance expression is always associated with a given objective and can be defined as a satisfaction degree. In fact, elementary performance expressions are returned by the so-called performance indicators. They result from the straightforward comparison between the objectives (obtained by the break-down of the overall objective considered) and the reached measurements (describing the actual business process or activity taking place). These measurements can be simple physical observations acquired in the form of single values (e.g. number of weeks between the order and the delivery), or obtained from the processing of several measurements (e.g. mean number of days of late shipments). Hence, the performance expressions can be formalized by the following mapping [27]:

$\mathrm{P}: O \times M \rightarrow E \quad(o, m) \rightarrow \mathrm{P}(o, m)=P$.

$O, M$ and $E$ are, respectively, the universes of discourse of the set of objectives $o$, the set of measures $m$ and the performance expression $P$. The key point in differentiating this kind of performance expression from conventional measurements is the comparison of the measurements acquired with an objective defined according to the control strategy considered. Thus, the mapping $\mathrm{P}$ is usually a ratio, a relative difference, or a normalized distance [27].

\subsection{Aggregated performance expressions}

\subsubsection{Generalities}

The aggregation of the performance expressions can be expressed as an operation that synthesizes the elementary performance expressions into an overall performance expression. Hence, the performance aggregation can be formalized by the following mapping:

$$
\begin{aligned}
& A g: E^{1} \times E^{2} \times \cdots \times E^{n} \rightarrow E \\
& \quad\left(P_{1}, P_{2}, \ldots, P_{n}\right) \rightarrow P_{\text {overall }}=\operatorname{Ag}\left(P_{1}, P_{2}, \ldots, P_{n}\right)
\end{aligned}
$$

$E^{i}$ is the universe of discourse of the elementary performance expressions $\left(P_{1}, \ldots, P_{n}\right)$ and $E$ is the universe of discourse of the overall performance expression $P_{\text {overall }}$.

As the performance expressions have a direct meaning in terms of objective satisfaction, the aggregation has to reflect how the elementary satisfactions make up the overall one. This leads to two main problems:

- defining commensurate elementary performance evaluations, i.e. having the same meaning, e.g. the satisfaction degree 0.80 for quality performance must mean the same thing as 0.80 for delivery time performance. The problem of commensurateness is not discussed in this paper for reason of length (see [26] for a detailed description). However, we have dealt with it using the MACBETH method [25]. It enables to check the scales on the $E^{i}, i=1, \ldots, n$ are interval scales and guarantees the consistency between the determination of weights and of elementary performance expressions. The mechanism ensuring the commensurateness is based on the definition by the decision-makers of two reference values in each $E^{i}$ having a common satisfaction meaning for all the criteria. Generally, the reference values correspond to 
totally unsatisfactory (0) and totally satisfactory (1) and they are associated to values of the universe of measures to anchor the comparison between different situations. The MACBETH method has initially been proposed in the framework of weighted mean aggregation operators. Then, it has been extended to the case of the Choquet Integral [16,28].

- defining the composition of the overall expression that takes interactions concerning the relationships between the elementary expressions (weights, mutual interactions) into account. For example, operator skilfulness in assembling kitchen elements and element availability at the operators' workstation have a mutual interaction with respect to the average delivery time of kitchen shipment.

\subsection{The Choquet integral aggregation operator}

Generally the performance criteria are characterized by subordination as well as transverse relations. The hierarchical structure of the performance criteria is not unlike the hierarchical organization of specialist units or consultants that are expected to distill the relevant and useful information in their area and forward it to the final decision maker. Furthermore, coalitions or conflicts constitute interaction phenomena that may influence the set of performance criteria. Transverse relations express coordination links that ensure the coherence of the satisfaction degrees at a given hierarchical level. New aggregation functions (w.r.t. the weighted average) must be added in order to benefit from this semantic distinction in the relations among criteria, for example the Choquet integral [29]. This operator is a good illustration of the aggregation of satisfaction degrees related by subordination and coordination dependencies: in particular, it allows modelling the relative importance of a criterion and its mutual interactions with the other ones. In our application, we consider only a particular case of Choquet fuzzy integrals, based on the so-called 2-additive measure [24]: in this simplified model, only interactions in pairs of criteria are considered. The 2-additive Choquet integral can then be expressed in the interpretable form as follows:

$$
\begin{aligned}
& A g_{\mathrm{CI}}\left(P_{1}, P_{2}, \ldots, P_{n}\right) \\
& \quad=\sum_{i=1}^{n} P_{i} \cdot v_{i}-\frac{1}{2} \cdot \sum_{i>j} I_{i j} \cdot\left|P_{i}-P_{j}\right|
\end{aligned}
$$

with the property that $\left(v_{i}-\frac{1}{2} \sum_{i \neq j}\left|I_{i j}\right|\right) \geqslant 0$, and where $v_{i}$ are the Shapley indices, representing the importance of each criterion relative to all the others, with $\sum_{i=1}^{n} v_{i}=$ $1 ; I_{i j}$ represents the interactions between pairs of the criteria $(i, j)$ with values contained in the interval $[-1 ; 1]$; a value 1 means a full complementarity between the two criteria, a value of -1 indicates a full redundancy, and a null value means the criteria are independent.

\section{Indexes for aiding the improvement monitoring}

\subsection{General approach}

As stated above, once an overall performance expression has been obtained, the problem is to help the decision-makers in their diagnosis and improvement analysis by considering

- The reasons, why a particular level of overall performance is observed, and how resources have been used on each performance criterion. The answer to this "how" question (which can be viewed as an efficiency analysis) can be commonly expressed in terms of the actual improvement realized on each elementary performance versus the minimal improvement required to reach the overall performance observed. Note that even when the overall performance is good, i.e. $A g_{\mathrm{CI}}\left(P^{k}\right) \approx 1$, the "how" question remains an important issue in order to avoid over-quality behavior or additional costs. Indeed, each elementary performance improvement is associated to a cost due to the consumed resources.

- The way this performance could be improved, i.e. the determination of the least costly improvement of the elementary performances. Indeed, decisionmakers generally know the actions that have to be carried out in order to increase one elementary performance (for example, according to the considered decisional level: working overtime, investing in new equipment, operator training...). Their problem is to design an action plan that will lead to the required overall performance improvement with a minimal increase w.r.t. each elementary performance, i.e. a minimal additional cost related to each of them.

The answers to the two preceding points are intuitive and simple when the aggregation operator is linear (the weighted mean for example). Therefore, our general approach is based on a linear expression for the Choquet integral in simplex regions. Indeed, as presented in Section 2, the Choquet integral is composed of a linear part that is modified according to mutual interaction between criteria. Furthermore, the 2-additive Choquet integral can be written as a conventional weighted mean in each simplex $H_{\sigma_{k}}=\left\{P \in[0,1]^{n} / 0 \leqslant P_{\sigma(1)}^{k} \leqslant \cdots \leqslant P_{\sigma(n)}^{k} \leqslant 1\right\}$ 
defined by the ranking of the elementary performances represented by the function $\sigma$; Akharraz et al. [30] have proved that this weighted sum can be simply expressed with the Shapley and interactions indices (see Eqs. (2) and (3)). Indeed, for any performance vector $P^{k}$ belonging to $H_{\sigma_{k}}$, the Choquet integral has the linear expression

$A g_{\mathrm{CI}}\left(P^{k}\right)=\sum_{i=1}^{n} \Delta \mu_{(i)}^{k} \cdot P_{(i)}^{k}$,

where

$\Delta \mu_{(i)}^{k}=v_{(i)}+\frac{1}{2} \sum_{j>i} I_{(i)(j)}-\frac{1}{2} \sum_{j<i} I_{(j)(i)}$

(the brackets around the indexes indicate the ranking) with $v_{(i)}$ the relative importance of criterion $c_{(i)}$ and $I_{(i)(j)}$ the interaction between criteria $c_{(i)}$ and $c_{(j)}$. Moreover, for every

$k: \sum_{i=1}^{n} \Delta \mu_{(i)}^{k}=1$.

Thus, the Choquet integral is a sort of weighted mean with weights varying according to the ranking of elementary performances. Therefore, mathematical tools developed in the linear framework can be extended, as detailed below.

\subsection{Efficiency analysis of the overall performance}

One important aspect of understanding the overall performance consists in providing evidence concerning the resources used to carry out an improvement action. This is aimed at achieving a particular overall performance expression from an initial one, e.g. going from 0.85 to 0.95 (in practice, null elementary performances for all criteria are rarely the initial state). This analysis is particularly important when the overall performance is good, because in this case it could seem that everything has gone right: however even when the objectives are reached, decision-makers must still verify that the corresponding resources expended by the organization correspond to the planned resources and that there has been no waste.

It is worth noticing that the sum of all the elementary performance variations made to achieve the new overall performance is considered here as a good indication of the resources consumed. Indeed the resources are clearly related to the required performance increase value on each criterion. For the sake of helping the reader to focus on the principles of our approach, we consider in this paragraph that a performance value increase has the same cost for each criterion. In practice, it is often not the case and therefore the cost aspect of each elementary improvement will be considered in Section 4, which leads to a slight modification of the calculations presented hereafter.

Let us now denote $\Delta^{*}$ the minimal increase of the sum (in the L1-norm sense).

$\|\delta\|_{1}=\sum_{i=1}^{n}\left|\delta_{i}\right|$

of the elementary performance increases $\delta_{i}$ required to go from an initial performance vector $P^{0}=\left(P_{1}^{0}, \ldots, P_{i}^{0}, \ldots, P_{n}^{0}\right)$ to a required overall performance in the range $\left[\mathrm{Ag}_{\mathrm{CI}}\left(P^{0}\right), 1\right]$ denoted $P_{\text {overall }}^{*}$.

It is thus defined as the optimization problem (P1):

Objective function

$\Delta^{*}=\min \|\delta\|_{1}$

Constraint:

$A g_{\mathrm{CI}}\left(P_{1}^{0}+\delta_{1}, \ldots, P_{n}^{0}+\delta_{n}\right)=P_{\text {overall }}^{*}$

Bound constraints:

$0 \leqslant \delta_{i} \leqslant 1-P_{i}^{0} \quad \forall i \in\{1, \ldots, n\}$.

The details of the increase vector $\delta^{*}=\left(\delta_{1}^{*}, \delta_{2}^{*}, \ldots, \delta_{n}^{*}\right)$ associated to $\Delta^{*}$ are quite complex [31]. The solving principle of (P1) is based on the linearity of the Choquet integral in each simplex $H_{\sigma}$ associated to a given ranking of the elementary performances: the nonlinear problem (P1) can be decomposed into linear problems when additional bound constraints are added. In each $H_{\sigma}$, the (P1) solving problem is reduced to a simplex algorithm.

As, in practice, the manager uniquely tries to reach an overall expected performance $P_{\text {overall }}^{*}$, the elementary increases $\delta_{j}^{\text {observed }}$ actually performed are not always optimally achieved. Therefore, in order to define the overall efficiency, we propose computing the ratio of the minimal increase sum $\Delta^{*}$ w.r.t. the actually performed increase sum $\left\|\delta^{\text {observed }}\right\|_{1}$ :

$\Delta^{*} /\left\|\delta^{\text {oberved }}\right\|_{1}$

the closer to 1 this ratio is, the more efficient the improvement is.

Going further in the understanding of performance improvement, we propose defining the efficiency of an elementary performance increase by the difference between the observed increase $\delta_{j}^{\text {observed }}$ and the minimal elementary increase contribution denoted $\delta_{j}^{*}$. A positive difference indicates that the elementary improvement relative to criterion $j$ is too high and thus not relevant: too many resources have been consumed and 
thus wasted w.r.t. this criterion and over-quality should be diagnosed for criterion $j$. When the difference is negative, the improvement w.r.t. criterion $j$ is insufficient and thus indicates that further resources should be necessary to achieve this elementary objective. ${ }^{1}$ Lastly, when the difference is null the way the objective is reached w.r.t. this criterion is optimal.

These indexes then provide the decision-maker with indications about the criterion for which:

- he/she can reduce the investment because the organization policy is too generous regarding this criterion;

- he/she is compelled to increase investment to meet a particular expectation because he/she was initially too ambitious with respect to the means invested in that problem criterion;

- he/she should simply maintain investment because a satisfactory state has been reached by the organization and the objective is reached at a minimal cost.

\subsection{Predictive improvement analysis}

Once the required overall performance improvement is known, an important issue is the determination of the most "relevant" elementary performances to improve to reach the overall performance. The above-mentioned algorithm for efficiency computation can be used for this purpose in a reverse interpretation, i.e. this time an improved value $P_{\text {overall }}^{*}$ is expected and the minimum increase required for each elementary performance is to be computed.

Another aspect concerns the introduction of a unitary $\operatorname{cost} c_{i}$ for improving performance w.r.t. criterion $i$. This aspect can be tackled by modifying the expression (2) $\|\delta\|_{1}=\sum_{i=1}^{n}\left|\delta_{i}\right|$ by adding cost coefficients $c_{i}$, i.e. having

$$
\left\|\delta^{c}\right\|=\sum_{i=1}^{n} c_{i}\left|\delta_{i}\right| .
$$

Then the same algorithm can be applied. This modification is useful at the practical level (as only small variations are considered, constant cost coefficients are a realistic model). This situation is considered in the case study detailed in the next section.

\section{Case study}

\subsection{Context of the application}

The case study concerns a company of 900 persons manufacturing kitchen and bathroom furniture

\footnotetext{
${ }^{1}$ A close but different interpretation of these calculations in terms of energy has been proposed in [19].
}

and storage closets. The company manufactures more than 850,000 items, and its weekly production is 5000 units. The manufacturing process is partly automated, being made up of 10 major activities (manufacturing, injection, assembly, finishing, packaging, dispatching...). The product is made of about 10 different items, each item containing from 10 to 50 elementary parts. The manufacturing cycle time ranges from 2 to 5 weeks. Since many years, the company has followed the Deming wheel philosophy to develop a continuous improvement approach of its processes based on performance indicators developed according to the ISO 9000 standard.

In fact, the overall goal of the company is to increase profit margins. To achieve this, the company has defined for 2004 a strategic action plan, the "environment and quality plan", which includes, on the one hand, the different actions and improvements to be carried out regarding the manufacturing process and product quality and, on the other hand, the environmental constraints. More precisely, Table 1 below gives, respectively, the different strategic objectives ${ }^{2}$ of the company, the associated measures achieved and performance indicators. These sets of indicators are deployed on all the units of the company and the top-management team takes the production control decisions from the values provided by the indicators at the different levels. But, in order to aid their decisions, the management team are asking for a quantification of the interactions between the indicators at the different levels.

Therefore, the research team and the management team agreed to consider the strategic objective related to the service rate to implement the proposed approach for quantification. As stated earlier in this paper, the aim of this study is not to confine decision-makers to a narrow choice of performance indicators for assessing and controlling their processes, but to provide explanations about the overall performance. Thus, pieces of information concerning the best way to obtain a performance improvement (efficiency and minimizing costs) are needed. The suggested approach is therefore: firstly to carry out a logical top-down objective decomposition, then to quantify the causal relationship, i.e. Choquet weights and interactions and elementary performances, and finally to implement a bottom-up performance aggregation mechanism, and secondly to compute the proposed indexes for efficiency and predictive improvement analysis.

\footnotetext{
${ }^{2}$ Let us remember that, from a formal point of view, an objective can be defined as a set of numeric or linguistic values associated to a variable or criterion, according to the control loop principle [2].
} 
Table 1

The strategic objectives and indicators of the company

\begin{tabular}{lll}
\hline Criterion & $\begin{array}{l}\text { Expected value/ } \\
\text { current value }\end{array}$ & Performance indicator (PI) \\
\hline Service rate & $97.5 \%$ & $p_{\text {SR }}=\frac{\text { Number of in-conformity orders being deliverd in time }}{\text { Total number of orders }}$ \\
After-sales service & $95 \%$ & $p_{\text {ASS }}=\frac{\text { Exchanged product value }}{\text { Order value }}$ \\
Product offer & $1.2 \%$ & $p_{\text {PO }}=$ Width and depth of the range \\
Delivery time & $1.35 \%$ & $p_{\mathrm{DT}}=$ Number of weeks between the order and the delivery \\
Very satisfactory & $\begin{array}{l}\text { Satisfactory } \\
8-10 \text { weeks }\end{array}$ & \\
& $8-13$ weeks & $p_{\mathrm{SC}}=$ Aggregation of the various employees' perception \\
& Satisfactory &
\end{tabular}

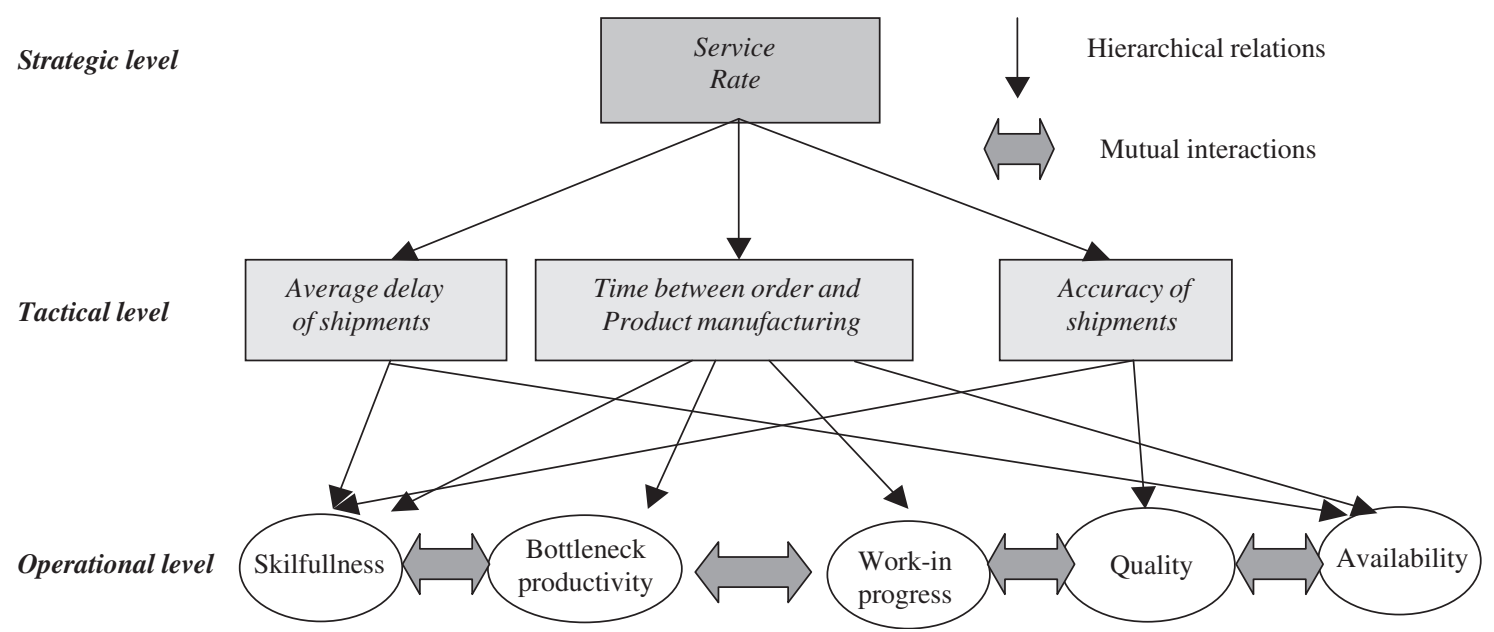

Fig. 1. Performance structure of the strategic service rate objective.

\subsection{The company service rate PMS}

\subsubsection{Methodology of design}

Previously to the collaboration between the research team and the management team, the latter had designed a PMS for the service rate by using a conventional approach $[1,27]$. This approach consists in: analyzing the process, selecting the critical activities, identifying the improvement factors, defining the performance indicators and the potential actions. Thus the service rate strategic objective has been broken down from the top-management to the tactical and operational levels of the hierarchical decisional structure of the company (see Fig. 1).

\subsubsection{Quantification}

Table 2 below, respectively, gives the different tactical and operational values for the Service rate objective, performance indicators, and commensurate performance evaluations. Indeed, with respect to product standards, the achieved performances have been expressed directly by the management team. Then, the values provided by the performance indicators (denoted $p$ ) have to be transformed into commensurate performance evaluations (denoted $p^{\mathrm{e}}$ ) for the different criteria before being aggregated. This transformation was performed using the Macbeth method extended to the 2-additive Choquet integral case [16,24].

Hence, the service rate objective is decomposed into three tactical independent objectives having the same importance and five operational ones, having different weights indicated in Table 3.

Moreover, according to the production manager's knowledge about the process, there are positive $(++$ or + ), null $(0)$ or negative $(--$ or - ) interactions between the different criteria. For the sake of simplicity, 
Table 2

The tactical and operational objectives and indicators related to the service rate

\begin{tabular}{|c|c|c|c|}
\hline Criterion & $\begin{array}{l}\text { Expected } \\
\text { value }\end{array}$ & Performance indicator $(\mathrm{PI})$ & $\begin{array}{l}\text { Current value } \\
\text { performance evaluation }\end{array}$ \\
\hline Service rate & $97.5 \%$ & $p_{\mathrm{SR}}=\frac{\text { Number of in-conformity orders being delivered in time }}{\text { Total number of orders }}$ & $95 \%$ \\
\hline Average delivery time & 0.5 & $p_{\mathrm{NDLS}}=$ Mean number of days of late shipments & $\begin{array}{l}p_{\mathrm{SR}}^{\mathrm{e}}=0.80 \\
5 \text { days } \\
p_{\mathrm{NDLS}}^{\mathrm{e}}=0.45\end{array}$ \\
\hline $\begin{array}{l}\text { Time between order } \\
\text { and reception }\end{array}$ & 6 weeks & $\begin{array}{l}p_{\mathrm{TBOR}}=\text { Time between the exit of the raw materials } \\
\text { and the storage of the finished product }\end{array}$ & $\begin{array}{l}8 \text { weeks } \\
p_{\mathrm{TBOR}}^{\mathrm{e}}=0.60\end{array}$ \\
\hline Accuracy of shipments & $99 \%$ & $p_{\text {AS }}=\frac{\text { Number of in-conformity orders }}{\text { Total number of orders }}$ & $97 \%$ \\
\hline Skilfulness & 1.5 & $p_{s}=\frac{\text { Number of operators able to work per equipment }}{\text { Number of equipments }}$ & $\begin{array}{l}p_{\mathrm{AS}}^{\mathrm{c}}=0.30 \\
\text { 1operat/equipt }\end{array}$ \\
\hline Bottleneck productivity & $\begin{array}{l}\text { op./equipt } \\
60 \text { items } / \mathrm{h}\end{array}$ & $\begin{array}{l}p_{\mathrm{BP}}=\text { Number of items manufactured, per hour, } \\
\text { by the assembly activity }\end{array}$ & $\begin{array}{l}p_{\mathrm{S}}^{\mathrm{e}}=0 \\
50 \text { items } / \mathrm{h} \\
p_{\mathrm{BP}}^{\mathrm{e}}=0.50\end{array}$ \\
\hline Work-in-progress level & 0.5 week & $p_{\mathrm{WIP}}=$ Duration of the work in progress & $\begin{array}{l}1-2 \text { weeks } \\
p_{\mathrm{WIP}}^{\mathrm{e}}=0.75\end{array}$ \\
\hline Quality & $98 \%$ & $p_{\mathrm{Q}}=\frac{\text { Number of in-conformity items }}{\text { Total number of manufactured items }}$ & $\begin{array}{l}95 \% \\
p_{\mathrm{O}}^{\mathrm{e}}=0.60\end{array}$ \\
\hline Equipment availability & $95 \%$ & $p_{\mathrm{EA}}=\frac{\mathrm{Up} \text { time }+ \text { waiting time }}{\text { Opening time }}$ & $p_{\mathrm{EA}}^{\mathrm{e}}=0.60$ \\
\hline
\end{tabular}

Table 3

The weights of the different performance criteria

\begin{tabular}{llll}
\hline Operational PI & \multicolumn{2}{l}{ Tactical objectives } & \\
\cline { 2 - 4 } & Average delivery time & Time between order and reception & Accuracy of shipments \\
\hline Skilfulness (1) & 0.20 & 0.20 & 0.50 \\
Bottleneck productivity (2) & & 0.35 & 0.50 \\
Work in progress (3) & & 0.35 & 0.10 \\
Quality & 0.80 & 0.10 & \\
Equipment availability (4) & & & \\
\hline
\end{tabular}

in this paper we will consider only the aggregation of the operational performances to obtain the tactical performance on time between order and reception. The associated interactions are indicated in Table 4. The symbols + and - have been transformed into interaction values between $[-1 ;+1]$ by applying a coefficient of $\frac{1}{8}$ (resp. $-\frac{1}{8}$ ) to the sum of the weights of the interacting criteria when + (resp. - ) is present and $\frac{1}{4}$ for ++ (resp. $-\frac{1}{4}$ for --$)$. Thus, the associated Choquet integral parameters are $v_{1}=0.20, v_{2}=0.35, v_{3}=0.35, v_{4}=0.10$, and $I_{12}=0.07, I_{13}=0.13, I_{14}=0.07, I_{23}=-0.08$, $I_{24}=-0.06$, the others being equal to 0 .

In order to improve the different elementary performances, the company can define many actions from the "quality and environment plan" (the actions are gathered in Table 5).
Naturally, the cost of improving one unit of performance varies according to the criteria considered. Indeed, carrying out the different improvement actions does not have the same cost, according to the allocated resource (human or material), the duration, etc. Table 5 indicates these action costs on a 1-10 scale.

Note that the precise evaluation of the action costs is quite difficult for the management team. Thus the values reported in Table 5 are approximate and they have to be changed in the simulation in order to consider their sensitivity.

\subsection{Efficiency analysis}

Let us consider now the following situation observed in April $P^{\text {april }}=\left(P_{1}^{\text {april }}=0.55, P_{2}^{\text {april }}=0.60, P_{3}^{\text {april }}=0.80\right.$, 
Table 4

The interactions between the different operational criteria

\begin{tabular}{lllll}
\hline & Skilfulness & Bottleneck productivity & Work in progress & Quality \\
\hline Skilfulness & & + & ++ & ++ \\
Bottleneck productivity & + & - & - & - \\
Work in progress & ++ & - & 0 & 0 \\
Quality & ++ & - & 0 & + \\
Equipment availability & ++ & + & + \\
\hline
\end{tabular}

Table 5

The different improvement action costs

\begin{tabular}{lll}
\hline Action & Cost/perf. unit & Variation \\
\hline Autonomous teamwork & 9 & Linear with the person number \\
Identification and improvement of the critical equipment & 7 & Linear \\
Sizing the strategic WIP & 1 & Linear \\
Increasing quality control & 3 & Linear \\
Implementing an on-site maintenance & 3 & Discrete $(0,1)$
\end{tabular}

$\left.P_{4}^{\text {april }}=0.70\right)$ which leads to $A g_{\mathrm{CI}}\left(P^{\text {april }}\right)=0.66$. As this overall performance was not satisfactory, an action plan was designed and implemented for a period of one month. Some actions were implemented with regard to the training of operators on different types of equipment, in order to improve their skilfulness. The following new elementary "poor" performances were then observed in May: $P^{\text {may }}=\left(P_{1}^{\text {may }}=0.85, P_{2}^{\text {may }}=0.65, P_{3}^{\text {may }}=0.80\right.$, $\left.P_{4}^{\text {may }}=0.70\right)$ which leads to $A g_{\mathrm{CI}}\left(P^{\text {may }}\right)=0.74$, i.e. an overall improvement of 0.08 for a sum of elementary performance increases of $0.30+0.05+0+0=0.35$. Indeed, the training produced limited effects and little motivated the operators. But, this sum has to be compared with the minimal sum enabling to reach a value of 0.74 for the overall performance from an initial value of 0.66 . Applying the algorithm described in Section 3 leads to the following minimal increase vector:

$\delta^{*}=\left(\delta_{1}^{*}=0.0, \delta_{2}^{*}=0.13, \delta_{3}^{*}=0.0, \delta_{4}^{*}=0.0\right)$

which gives the minimal sum $\Delta^{*}=0.13$.

Thus the overall efficiency is $0.13 / 0.35=37 \%$. The respective efficiencies for the elementary performances skilfulness, bottleneck productivity, work in progress and equipment availability are: $+0.30,-0.08$, $+0.0,+0.0$. The overall performance was improved, but the distribution of elementary performance improvement was not optimum.

Note that this result is based on the assumption of the same improvement cost for each criterion. If we take the real costs into account (see Table 5) we obtain:

$\delta^{\mathrm{c} *}=\left(\delta_{1}^{\mathrm{c} *}=0.0, \delta_{2}^{\mathrm{c} *}=0.0, \delta_{3}^{\mathrm{c} *}=0.15, \delta_{4}^{\mathrm{c} *}=0.0\right)$

and $\Delta^{\mathrm{c} *}=0.03$ (over a range of $[0,4]$ ),

when we have: $\delta^{\mathrm{c}}=\left(\delta_{1}^{\mathrm{c}}=0.30, \delta_{2}^{\mathrm{c}}=0.05, \delta_{3}^{\mathrm{c}}=\right.$ $\left.0.0, \delta_{4}^{\mathrm{c}}=0.0\right)$ and $\Delta^{\mathrm{c}}=0.61$ for the action plan considered. Thus the cost of improvement was much higher than the minimal one, which is explained by the high cost of improvement of the skilfulness criterion.

\subsection{Predictive improvement analysis}

Once a situation has been analyzed, the problem at the management level is to determine, from the "quality and environment plan", the action plan to be carried out to obtain a fixed performance improvement at the lowest cost, e.g. to reach a better overall performance in June $P_{\text {overall }}^{\text {june }}=0.95$ from the preceding poor one $P_{\text {overall }}^{\text {may }}=$ 0.74 . From a mathematical point of view, as mentioned before, this leads to the application of the preceding algorithm by integrating the improvement costs relative to each criterion as weights in the increased performance sum $\Delta$ (see Section 3.3). Indeed starting from the situation $P^{\text {may }}=\left(P_{1}^{\text {may }}=0.85, P_{2}^{\text {may }}=0.65, P_{3}^{\text {may }}=\right.$ $\left.0.80, P_{4}^{\text {may }}=0.70\right)$ which leads to $A g_{\mathrm{CI}}\left(P^{\text {may }}\right)=0.74$, with the improvement objective $P_{\text {overall }}^{*}=0.95$, we ob$\operatorname{tain} \delta^{\mathrm{c} *}=\left(\delta_{1}^{\mathrm{c} *}=0.0, \quad \delta_{2}^{\mathrm{c} *}=0.34, \quad \delta_{3}^{\mathrm{c} *}=0.20, \quad \delta_{4}^{\mathrm{c} *}=0.0\right)$ and $\Delta^{\mathrm{c} *}=0.52$. Therefore, the priority of action concerns first bottleneck productivity, and second work in progress. 
In addition, if we had wanted to reach $P_{\text {overall }}^{\text {june }}=0.95$ directly from $A g_{\mathrm{CI}}\left(P^{\text {april }}\right)=0.66$ with $P^{\text {april }}=\left(P_{1}^{\text {april }}=\right.$ $\left.0.55, P_{2}^{\text {april }}=0.60, P_{3}^{\text {april }}=0.80, P_{4}^{\text {april }}=0.70\right)$, we would have obtained $\delta^{\mathrm{c} *}=\left(\delta_{1}^{\mathrm{c} *}=0.0, \delta_{2}^{\mathrm{c} *}=0.40, \delta_{3}^{\mathrm{c} *}=\right.$ $\left.0.20, \delta_{4}^{\mathrm{c} *}=0.17\right)$ and $\Delta^{\mathrm{c} *}=0.70$. In this case, the priority of action would have been first bottleneck productivity, and second work in progress and equipment availability. Note that, making the improvement in the two considered steps: 0.66 in April- $>0.74$ in May->0.95 in June) leads to a total cost of $0.61+0.52=1.12$ when the total cost is 0.70 for one direct step. In conclusion, a costly operator training action is not required to reach an overall performance $P_{\text {overall }}=0.95$, but note that it could be mandatory to obtain a higher value. In addition, the order of the sequence of improvements has an influence on the total cost.

\subsection{Discussion}

A method for quantifying the causal relationships between the various criteria affecting the service rate performance has been developed and implemented. For the management team the most important benefit is the expression of heterogeneous performance measures into a dimensionless unit at all the company levels. It has provided a better understanding of the performance for all the people involved in the continuous improvement program. The management team was already familiar with the comparison of situations and a consensus was rapidly reached with the help of the research team for determining the aggregation parameters.

Nevertheless the time needed for this phase (one day in two consecutive weeks) does not allow to apply this procedure frequently. The second benefit is related to the decision making aid for launching the improvement actions. Managers often hesitate between different solutions and the proposed efficiency and predictive improvement indexes allow them to validate their intuition. Having an off line simulation tool that enables to consider different configurations of actions has raised significant interest. Indeed, the proposed approach not only allows to compare pre-defined action plans but also proposes advice to build new action plans. In other respects, the simulation has emphasized the fact that it is important to have a long term view of the overall performance required in order to design low-cost action plans. An adequate sequence of action can lead to significant cost reduction. But it requires having a better visibility of what and when it is possible to do particular actions in the year, especially with regard to additional temporary worker employment or orders for raw material.
We have also observed after a few months of use, that the management team slightly modifies the objective values. The main reasons are that

- they want to adjust the previously set values because they realize that they are too optimistic or too pessimistic; indeed the processes being complex it is difficult to a priori set the objectives with a very precise value;

- the environment has slightly evolved and the objectives have to be revised.

This latter aspect is related to the notion of (DPMS) introduced by Bititci [32]. Our method has some flexibility for dealing with internal and/or external environment changes but only under the assumptions of small variations of the objective values and of the importance and interactions of the performance criteria. Important changes require a new complete analysis of the performance structure and of the associated quantification, which requires a few days to be conducted. Nevertheless, the introduction of a sensitivity analysis in our multi-criteria method would provide a significant gain for aiding decision-making in medium varying situations.

Finally, the proposed approach is not specific to the case considered. It can be applied across different sectors of industry where the decision-makers have sufficient knowledge concerning specific situations that are essential to define the importance and interactions of criteria. The method is particularly relevant for situations where the overall performance improvement is obtained by a continuous succession of small local performance improvements to be carried out in an adequate sequence.

\section{Conclusion}

The propositions of this paper originated from the industrial production managers' demand for an aid to better monitor improvement action plans when there are faced with interacting multi-criteria objectives. From a quantitative modeling of performance measurement systems (PMS) based on a Choquet integral aggregation, an efficiency index has been proposed. It allows managers to have a better understanding of this more complex (i.e. nonlinear) performance model. In addition, the optimization algorithm presented can be used to determine the optimal distribution of resources on performance criteria in order to reach an expected overall performance improvement. The decision-aiding functionalities have been integrated in the PMS dedicated 
to the "quality and environment plan" of a manufacturing company. Though an important benefit can be obtained from this quantified model, a few limitations might be considered. They relate to the quality of the model identification, i.e. the relevance of the Choquet integral parameters. Indeed, the proposed approach requires a large manager expertise of the process: to build the structure of the overall performance, to deploy the overall objectives into tactical and operational ones, and to compare a number of performance situations in order to identify the Choquet parameters through an extension of the Macbeth method. This knowledge is not always available, especially when important internal or external changes in the company environment occur.

Perspectives for future research will concern improvement indexes that include more demanding constraints on the elementary performance increases, e.g. minimal performance to be reached for specific criteria, or acting only on a single elementary performance.... In addition, in order to move one step forward in dealing with dynamic business environments, the implementation of a sensitivity analysis could help to identify when to review and change the structure, the objectives and the aggregation parameters within a PMS.

\section{References}

[1] Bititci US. Modelling of performance measurement systems in manufacturing enterprises. International Journal of Production Economics 1995;42:137-47.

[2] Berrah L, Cliville V, Harzallah M, Haurat A, Vernadat F. A cyclic enterprise reengineering method. International conference on engineering design and automation (EDA'01), Las Vegas, NV, USA, August 2001. 6pp., CD-ROM.

[3] Neely A. The performance measurement revolution: why now and what next?. International Journal of Operations and Production Management 1999;19(2):205-28.

[4] Kueng P, Krahn AJ. Building a process performance measurement system: some early experiences. Journal of Scientific, and Industrial Research 1999;58:149-59.

[5] Santos SP, Belton V, Howick S. Adding value to performance measurement by using system dynamics and multi-criteria analysis. International Journal of Operations and Production Management 2002;22(11):1246-72.

[6] Diakoulaki D, Mavrotas G, Papagyannakis L. A multicriteria approach for evaluating the performance of industrial firms. Omega 1992;20(4):467-74.

[7] Lee H, Kwak W, Han I. Developing a business performance evaluation system: an analytic hierarchical model. Engineering Economist 1995;30(4):343-57.

[8] Rangone A. An analytical hierarchy process framework for comparing the overall performance of manufacturing departments. International Journal of Operations and Production Management 1996;16(8):104-19.
[9] Kim G, Park CS, Yoon KP. Identifying investment opportunities for advanced manufacturing systems with comparativeintegrated performance measurement. International Journal of Production Economics 1997;50:23-33.

[10] Suwignjo P, Bititci US. Quantitative models for performance measurement system. International Journal of Production Economics 2000;64:231-41.

[11] Mareschal B, Mertens D. Bankadviser: an industrial evaluation system. European Journal of Operational Research 1991;54: 318-24.

[12] Babic Z, Plazibat N. Ranking of enterprises based on multicriteria analysis. International Journal of Production Economics 1998;56-57:29-35.

[13] Globerson S. Issues in developing a performance criteria system for an organisation. International Journal of Production Research 1985;23(4):639-46.

[14] Browne J, Devlin J, Rolstadas A, Andersen B. Performance measurement: the ENAPS approach. International Journal of Business Transformation 1997;69(2):73-84.

[15] Grabot B. Objective satisfaction assessment using neural nets for balancing multiple objectives. International Journal of Production Research 1998;36(6):2377-95.

[16] Cliville V, Berrah L, Mauris G. Information fusion in industrial performance: a 2-additive Choquet integral based approach. IEEE International Conference on Systems, Man and Cybernetics (SMC 04), La Haye, Pays-Bas, October 2004. 6pp., CD-ROM.

[17] Ghalayini AM, Noble JS, Crowe TJ. An integrated dynamic performance measurement system for improving manufacturing competitiveness. International Journal of Operations \& Production Management 1997;15:80-116.

[18] Krause O, Mertins K. Performance management. International conference on advances in production management systems, Berlin, Germany, September 6-10, 1999. p. 243-51.

[19] Montmain J, Denguir A, Tardy J. An interactive decisionmaking support system for organization management and diagnosis. Modeling, Computation and Optimization in Information Systems and Management Sciences, Metz, France, 2004: 512-17.

[20] Berrah L, Mauris G, Vernadat F. Information aggregation in industrial performance measurement: rationales, issues and definitions. International Journal of Production Research 2004;42(20):4271-93.

[21] Saaty T. The analytic hierarchy and the analytic network processes for the measurement of intangible criteria and for decision-making. In: Figueira J, Greco S, Ehrgott M, editors. MCDA, Multiple criteria decision analysis. Dordrecht, MA: Kluwer Academic Publishers; 2004. p. 345-407.

[22] Sarkis J. Quantitative models for performance measurement systems-alternate considerations. International Journal of Production Economics 2003;86(1):81-90.

[23] Berrah L, Mauris G, Foulloy L. The aggregation of industrial performance information by the Choquet fuzzy integral. In: Reznik L, Kreinovich V, editors. Soft computing in measurement and information acquisition. Physica-Verlag; 2003. p. 121-35.

[24] Grabisch M, Labreuche C. Fuzzy measures and integrals. In: Figueira J, Greco S, Ehrgott M, editors. MCDA, Multiple criteria decision analysis. Dordrecht, MA: Kluwer Academic Publishers; 2004. p. 563-608.

[25] Bana e Costa CA, Vansnick JC. Applications of the MACBETH approach in the framework of an additive aggregation model. Journal of Multi-Criteria Decision Analysis 1997;6(2):107-14. 
[26] Cliville V, Berrah L, Mauris G. Quantitative expression and aggregation of performance measurements based on the MACBETH multi-criteria method. International Journal of Production Economics 2007;105(1):171-89.

[27] Berrah L, Mauris G, Foulloy L, Haurat A. Global vision and performance indicators for an industrial improvement approach. Computers in Industry 2000;43:211-25.

[28] Grabisch M, Labreuche C, Vansnick JC. On the extension of pseudo-Boolean functions for the aggregation of interacting bipolar criteria. European Journal of Operational Research 2003;148:26-47.

[29] Grabisch M, Roubens M. The application of fuzzy integrals in multicriteria decision making. European Journal of Operational Research 1996;89:445-56.
[30] Akharraz A, Mauris G, Montmain J. A project decision support system based on an elucidative fusion system. Fifth international conference on information fusion (ICIF 02), Annapolis, USA, 2002. p. 593-99.

[31] Winston WL. Introduction to mathematical programming: applications \& algorithms. Duxbury Press (An Imprint of Wadsworth Publish Co.); 1995.

[32] Bititci US, Turner T. Dynamics of performance measurement systems. International Journal of Operations and Production Management 2000;6:692-704. 